\title{
Estimation of Surface Area of Papaya Fruits
}

\author{
R. M. Kher ${ }^{1 *}$, F. M. Sahu ${ }^{2}$, S. N. Singh ${ }^{1}$ and V. A. Patel ${ }^{1}$ \\ ${ }^{1}$ Department of Processing and Food Engineering, College of Agricultural Engineering and \\ Technology, Navsari Agricultural University, Dediapada-396450, India \\ ${ }^{2}$ Centre of excellence on Post-Harvest Technology, Navsari Agricultural University, \\ Navsari-396450, Gujarat, India \\ *Corresponding author
}

\section{A B S T R A C T}

\section{Keywords \\ Papaya, surface area, geometrical shape, obovate \\ Article Info \\ Accepted: \\ 25 October 2018 \\ Available Online: \\ 10 November 2018}

Surface area of fruits and vegetable are often estimated by assuming that they resemble a geometrical shape from which surface area can be mathematically calculated. A composite geometrical shape nearing to obovate shape was presumed for papaya fruit cultivars Red Lady and its geometrical shape was correlated with actual surface area (estimated by measuring the area of aluminium foil required to cover the fruit surface- wrapping and scanning method). Geometrical surface area was found to be more than 95 accurate when compared to wrapping and scanning method.

\section{Introduction}

The determination of surface area $\left(\mathrm{A}, \mathrm{m}^{2}\right)$ of fruit is necessary to quantify the damages caused by insects and microorganisms (Yang et al., 1997; Padmanaban et al., 1997; Timmer et al., 1998). Surface area is also important when expressing transfer of heat, water vapour, gases, pesticides and foliar nutrients in and out of fruits and vegetables. Surface area is also important to establish the relations, in different maturity stages, between photosynthetic activity and fruit development (Dias-Perez, 1998). Though, direct measurement of fruit surface area is important in these studies, but difficult, not very precise and usually destructive (Anadaraj \& Bhagavan
1983; Clayton et al., 1995). Moreover, exterior irregularities of many horticultural commodities makes it difficult estimate $\mathrm{A}$ and could potentially cause significant error in the estimation of transfer coefficients, proportional to the error in estimation of $\mathrm{A}$. Estimates of A are often made by calculating that of a geometric shape which is considered to be representative of the commodity. Such calculations for round shapes fruits such as orange, muskmelon have commonly been based on perfect spheres:

$$
A=4 \pi r^{2}
$$

Where, $r$ is fruit radius. 
For Non- spherical shapes of many fruits such as apple, pear, watermelon, papaya; selection of an appropriate value for $r$ is very difficult.

The aim of this study was to evaluate the geometrical method of surface area of papaya fruit at five different stages of maturity viz. Green $\left(\mathrm{S}_{1}\right)$, Colour break $\left(\mathrm{S}_{2}\right)$, Quarter Ripe: 5 $-25 \%$ yellow skin $\left(S_{3}\right)$, Half Ripe: $26-50 \%$ yellow skin $\left(\mathrm{S}_{4}\right)$ and Three Quarter Ripe: 51 $75 \%$ yellow skin $\left(\mathrm{S}_{5}\right)$.

\section{Materials and Methods}

Similar size papaya fruits cv. Red Lady was selected at random from Navsari Agricultural University Farms at different stages of maturity. Dimensional measurement of each fruits consisted of three perpendicular transverse measurements and three longitudinal measurements between the blossom end and stem end of the fruit with a digital Vernier calliper with an accuracy of 0.1 mm. Actual fruit area A was estimated by wrapping and scanning method which was a destructive method of measurement.

Each papaya fruit was cut open along their five longitudinal ridges and properly wrapped with aluminium foil from outer surface to cover the fruit surface. The aluminium foils were then cut along their ridges to obtain five leaves of aluminium foil, of the area equal to the curved surface area of the whole papaya fruit. The leaves of aluminium foils were then allowed to be scanned in a leaf area meter individually and total area of all five leaves were added and recorded.

The inaccuracies associated with flattening of curve surface were minimized by cutting into narrow pieces. Surface area of leaves of aluminium foil were calculated using two different instruments (1) Hand held laser leaf area meter and (2) WINDIAS Leaf Image Analyser to nearest $1 \mathrm{~mm}^{2}$. The readings obtained in both machines were then compared with geometrical surface area from assumed shape.

For calculation of geometrical surface area of papaya cv. Red Lady, from fruit measurement was based on the assumption that the fruit corresponded closely to the composite of the following geometrical forms (Figure 1): (1) a smaller conical section at the blossom end of the fruit $=A_{1},(2)$ a frustum of a cone next to blossom part $=A_{2}$ and (3) an inverted frustum of a cone at the stem end $=\mathrm{A}_{3}$.

For calculation of geometrical surface area, following formulas were used:

As $r_{1}=\frac{d_{1}}{2} ; r_{2}=\frac{d_{2}}{2} \quad$ and $\quad r_{3}=\frac{d_{3}}{2}$

$\mathrm{L}_{1}=\sqrt{\left(r_{1}\right)^{2}+\left(h_{1}\right)^{2}}$,

$\mathrm{L}_{2}=\sqrt{\left(r_{2}-r_{1}\right)^{2}+\left(h_{2}\right)^{2}}$ and

$\mathrm{L}_{3}=\sqrt{\left(r_{2}-r_{3}\right)^{2}+\left(h_{3}\right)^{2}}$

Conic section $=\mathrm{A}_{1}={ }^{\pi} \times \mathrm{r}_{1} \times \mathrm{L}_{1}$

Frustum of cone $=\mathrm{A}_{2}={ }^{\pi} \times\left(\mathrm{r}_{1}+\mathrm{r}_{2}\right) \times \mathrm{L}_{2}$

Inverted frustum of cone $=\mathrm{A}_{3}={ }^{\pi} \times\left(\mathrm{r}_{2}+\mathrm{r}_{3}\right) \times$ $\mathrm{L}_{3}+{ }^{\pi} \mathrm{r}_{3}{ }^{2}$

Total geometrical surface area of papaya fruit $=A_{1}+A_{2}+A_{3}$

$=\left[{ }^{\pi} \times \mathrm{r}_{1} \times \mathrm{L}_{1}\right]+\left[{ }^{\pi} \times\left(\mathrm{r}_{1}+\mathrm{r}_{2}\right) \times \mathrm{L}_{2}\right]+\left[{ }^{\pi} \times\left(\mathrm{r}_{2}\right.\right.$ $\left.\left.+\mathrm{r}_{3}\right) \times \mathrm{L}_{3}+{ }^{\pi} \mathrm{r}_{3}{ }^{2}\right]$

Where, $d_{1}, d_{2}$ and $d_{3}$ were three transverse diameters and $h_{1}, h_{2}$ and $h_{3}$ were longitudinal dimensions from blossom end to stem end. $\mathrm{L}_{1}$, $\mathrm{L}_{2}$ and $\mathrm{L}_{3}$ denote the lateral height of composite shapes. 


\section{Results and Discussion}

\section{Sample Calculation of Surface Area by Geometrical method}

Calculations of the surface area and of the volume of papaya were based on the assumption that the fruit corresponded closely to the composite of the following geometrical forms (Figure 1):

A smaller conical section at the blossom end of the fruit $=A_{1}$, A frustum of a cone next to blossom part $=\mathrm{A}_{2}$

An inverted frustum of a cone at the stem end $=\mathrm{A}_{3}$.

Let, for given treatment $\mathrm{C}_{1} \mathrm{~S}_{1}$ ( 0 day), the various measurement taken from the geometrical shape of papaya were as follows

\section{Surface Area}

$\mathrm{A}_{1}={ }^{\pi} \times \mathrm{r}_{1} \times \mathrm{L}_{1}$

$=3.14 \times 3.65 \times 4.5$

$=51.57 \mathrm{~cm}^{2}$

$\mathrm{A}_{2}={ }^{\pi} \times\left(\mathrm{r}_{1}+\mathrm{r}_{2}\right) \times \mathrm{L}_{2}$

$=3.14 \times(3.65+4.9) \times 6.5$

$=174.51 \mathrm{~cm}^{2}$

$\mathrm{A}_{3}={ }^{\pi} \times\left(\mathrm{r}_{2}+\mathrm{r}_{3}\right) \times \mathrm{L}_{3}+{ }^{\pi} \mathrm{r}_{3}{ }^{2}$

$=3.14 \times(4.9+3.50) \times 5.5+3.14 \times(3.50)^{2}$

$=183.53 \mathrm{~cm}^{2}$

$\mathrm{A}=\mathrm{A}_{1}+\mathrm{A}_{2}+\mathrm{A}_{3}$

$=51.57+174.51+183.53$

$=409.61 \mathrm{~cm}^{2}$

Calculation of surface area by wrapping and scanning method

It was a destructive method of measurement, hence was carried out after completion of all other parameters needed from the whole fruit. The fruit was cut open along their five longitudinal ridges and properly wrapped with aluminium foil from outer surface. The aluminium foils were then cut along their ridges to obtain five leaves of aluminium foil, of the area equal to the curved surface area of the whole papaya fruit. The leaves of aluminium foils were then allowed to be scanned in a leaf area meter individually and total area of all five leaves were added and recorded. Surface area of leaves of aluminium foil were calculated using two different instruments (1) Hand held laser leaf area meter and (2) WINDIAS Leaf Image Analyser. The readings obtained in both machines were also compared.

\section{Surface area $\left(\mathrm{cm}^{2}\right)$}

The data pertaining to surface area (Geometrical) of papaya are presented in Table 1 and depicted in Figure 2. A sample calculation of geometrical area of papaya based on our assumed geometrical shape is presented in above equation. The mean surface area papaya fruit cv. Red Lady at stages $1\left(\mathrm{C}_{1} \mathrm{~S}_{1}\right)$ was $643.40 \mathrm{~cm}^{2}$ with a minimum value of $637 \mathrm{~cm}^{2}$ and maximum value of $649.76 \mathrm{~cm}^{2}$. Similarly, mean fruit mean surface area papaya at stages $2\left(\mathrm{C}_{1} \mathrm{~S}_{2}\right)$, $3\left(\mathrm{C}_{1} \mathrm{~S}_{3}\right), 4\left(\mathrm{C}_{1} \mathrm{~S}_{4}\right)$ and $5\left(\mathrm{C}_{1} \mathrm{~S}_{5}\right)$ were 612.34 , $474.45,652.14$ and $491.70 \mathrm{~cm}^{2}$, respectively. For cv. Local, The mean fruit mean surface area papaya at stages $1\left(\mathrm{C}_{2} \mathrm{~S}_{1}\right)$ was $409.61 \mathrm{~cm}^{2}$ with a minimum value of $404.56 \mathrm{~cm}^{2}$ and maximum value of $413.45 \mathrm{~cm}^{2}$. Similarly, mean fruit mean surface area papaya at stages $2\left(\mathrm{C}_{2} \mathrm{~S}_{2}\right), 3\left(\mathrm{C}_{2} \mathrm{~S}_{3}\right), 4\left(\mathrm{C}_{2} \mathrm{~S}_{4}\right)$ and $5\left(\mathrm{C}_{2} \mathrm{~S}_{5}\right)$ were $436.89,400.88,401.32$ and $351.88 \mathrm{~cm}^{2}$, respectively. From data it was evident that, the mean surface area papaya of papaya in both the cultivar did not vary significantly with ripening stages but mean surface area papaya of cv. Red Lady were significantly higher than cv. Local for all ripening stages. 


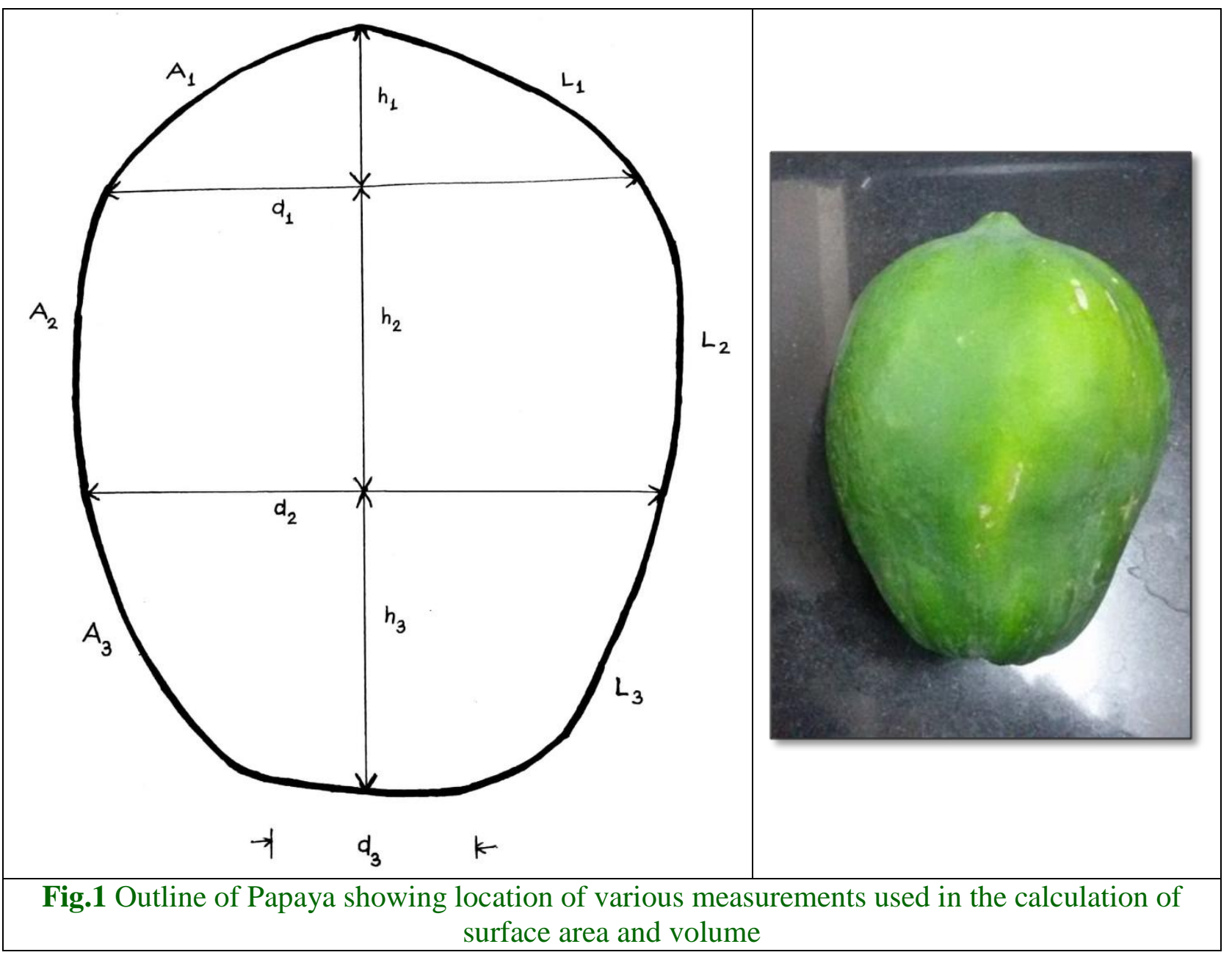

Fig.1 Surface area $\left(\mathrm{cm}^{2}\right)$ of papaya at different ripening stages

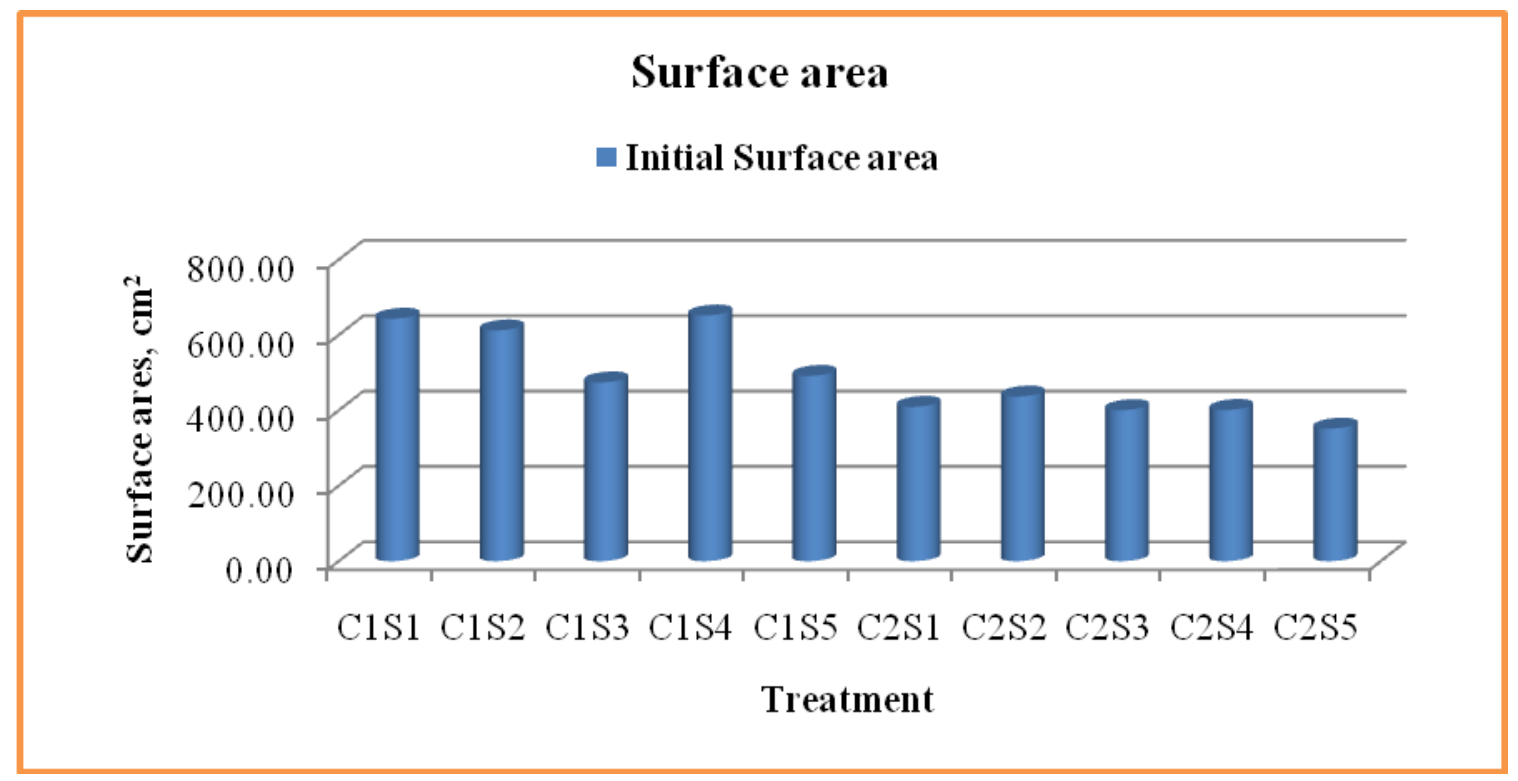


The various measurement taken from the geometrical shape of papaya

\begin{tabular}{|c|c|c|c|c|c|}
\hline Radius & $\mathbf{c m}$ & Surface Length & $\mathbf{c m}$ & Height & cm \\
\hline $\mathbf{r}_{1}$ & 3.65 & $\mathrm{~L}_{1}$ & 4.5 & $\mathrm{~h}_{1}$ & 4.2 \\
\hline $\mathbf{r}_{\mathbf{2}}$ & 4.9 & $\mathrm{~L}_{2}$ & 6.5 & $\mathrm{~h}_{2}$ & 6.5 \\
\hline $\mathbf{r}_{\mathbf{3}}$ & 3.5 & $\mathrm{~L}_{3}$ & 5.5 & $\mathrm{~h}_{3}$ & 5.3 \\
\hline
\end{tabular}

Table.1 Surface area $\left(\mathrm{cm}^{2}\right)$ of papaya at different ripening stages

\begin{tabular}{|c|c|c|c|}
\hline Treatment & Mean & Min & $\operatorname{Max}$ \\
\hline$C_{1} S_{1}$ & 643.40 & 637.00 & 649.76 \\
\hline $\mathrm{C}_{1} \mathrm{~S}_{2}$ & 612.34 & 609.40 & 614.72 \\
\hline $\mathrm{C}_{1} \mathrm{~S}_{3}$ & 474.45 & 471.00 & 476.90 \\
\hline $\mathrm{C}_{1} \mathrm{~S}_{4}$ & 652.14 & 650.25 & 654.16 \\
\hline $\mathrm{C}_{1} \mathrm{~S}_{5}$ & 491.70 & 489.60 & 493.00 \\
\hline $\mathrm{C}_{2} \mathrm{~S}_{1}$ & 409.61 & 404.56 & 413.45 \\
\hline $\mathrm{C}_{2} \mathrm{~S}_{2}$ & 436.89 & 432.82 & 441.85 \\
\hline $\mathrm{C}_{2} \mathrm{~S}_{3}$ & 400.88 & 400.00 & 402.50 \\
\hline $\mathrm{C}_{2} \mathrm{~S}_{4}$ & 401.32 & 398.27 & 403.20 \\
\hline $\mathrm{C}_{2} \mathrm{~S}_{5}$ & 351.88 & 345.00 & 358.00 \\
\hline Mean & 487.46 & 483.79 & 490.75 \\
\hline \multicolumn{4}{|c|}{ ANOVA Table } \\
\hline Source & S.Em. \pm & CD at $5 \%$ & CV \% \\
\hline$C^{*}$ & 0.983 & 2.9 & \multirow{3}{*}{0.4} \\
\hline S & 1.555 & 4.58 & \\
\hline $\mathrm{C} \times \mathrm{S}$ & 2.19 & 6.48 & \\
\hline
\end{tabular}

Table.2 Comparison of geometrical surface area $\left(\mathrm{cm}^{2}\right)$ of papaya at different ripening stages with different scanning methods

\begin{tabular}{|l|c|c|c|c|c|}
\hline Treatment & GSA $\left(\mathbf{c m}^{2}\right)$ & LIASA $\left(\mathbf{c m}^{2}\right)$ & LLAMSA $\left(\mathbf{c m}^{2}\right)$ & $\frac{G S A}{\text { LIASA }}$ & $\frac{\text { GSA }}{(\%)}$ \\
\hline $\mathbf{C}_{\mathbf{1}} \mathbf{S}_{\mathbf{1}}$ & 643.40 & 660.12 & 658.33 & 97.47 & 97.73 \\
\hline $\mathbf{C}_{\mathbf{1}} \mathbf{S}_{\mathbf{2}}$ & 612.34 & 649.19 & 625.94 & 94.32 & 97.83 \\
\hline $\mathbf{C}_{\mathbf{1}} \mathbf{S}_{\mathbf{3}}$ & 474.45 & 493.7 & 480.55 & 96.10 & 98.73 \\
\hline $\mathbf{C}_{\mathbf{1}} \mathbf{S}_{\mathbf{4}}$ & 652.14 & 670.8 & 664.37 & 97.22 & 98.16 \\
\hline $\mathbf{C}_{\mathbf{1}} \mathbf{S}_{\mathbf{5}}$ & 419.70 & 431.07 & 425.69 & 97.36 & 98.59 \\
\hline $\mathbf{C}_{\mathbf{2}} \mathbf{S}_{\mathbf{1}}$ & 409.61 & 422.2 & 417.88 & 97.02 & 98.02 \\
\hline $\mathbf{C}_{\mathbf{2}} \mathbf{S}_{\mathbf{2}}$ & 436.89 & 447.5 & 446.96 & 97.63 & 97.75 \\
\hline $\mathbf{C}_{\mathbf{2}} \mathbf{S}_{\mathbf{3}}$ & 400.88 & 427.5 & 402.82 & 93.77 & 99.52 \\
\hline $\mathbf{C}_{\mathbf{2}} \mathbf{S}_{\mathbf{4}}$ & 401.32 & 410 & 405.07 & 97.88 & 99.07 \\
\hline $\mathbf{C}_{\mathbf{2}} \mathbf{S}_{\mathbf{5}}$ & 351.88 & 373.1 & 366.19 & 94.31 & 96.09 \\
\hline
\end{tabular}


The surface area is a relevant tool in determining the shape of the fruit. This will actually be an indication of the way the fruit will behave on oscillating surfaces during processing. Similar data on surface area of papaya fruit were reported by Athmaselvi et $a l$. , (2013).The data pertaining to surface area were also determined by other method i.e wrapping and scanning method by using two different instruments such as WINDIAS Leaf Image Analyser (LIA) and Hand held laser leaf area meter (LLAM) and estimated.

Results were compared with geometrical surface area and depicted in Table 2 as ratio of Geometrical surface area (GSA) and surface area by Leaf Image Analyser (LIASA) and ratio of Geometrical surface area (GSA) and surface area by laser leaf area meter (LLAMSA)

From the data pertaining to comparative surface area depicted in Table 2 it can be inferred that surface area estimated by wrapping and scanning method in laser leaf area meter and leaf Image analyser provided nearby similar results. When the geometric area surface area of papaya for each cultivar are compared with surface area by Leaf Image Analyser (LIASA), they were accurate up to $97.88 \%\left(\mathrm{C}_{2} \mathrm{~S}_{4}\right)$ with a lowest accuracy of 93.77\% $\left(\mathrm{C}_{2} \mathrm{~S}_{3}\right)$ for cv. Local and accuracy for cv. Red Lady ranges from $94.32 \%\left(\mathrm{C}_{1} \mathrm{~S}_{2}\right)$ to $97.47 \%\left(\mathrm{C}_{1} \mathrm{~S}_{1}\right)$. Similarly, when the geometric area surface area of papaya for each cultivar are compared with Surface area by hand held Laser Leaf Area Meter (LLAMSA), they are accurate up to $99.52 \%\left(\mathrm{C}_{2} \mathrm{~S}_{3}\right)$ with a lowest accuracy of $96.09 \%\left(\mathrm{C}_{2} \mathrm{~S}_{5}\right)$ for $\mathrm{cv}$. Local and accuracy for cv. Red Lady ranges from $97.73 \%\left(\mathrm{C}_{1} \mathrm{~S}_{1}\right)$ to $98.73 \%\left(\mathrm{C}_{1} \mathrm{~S}_{3}\right)$. From above results, it can be inferred that geometrical surface area of both cultivar were at par with wrapping and scanning method with the assumed geometrical shape, thereby it is evident that assumed shape enable us to describe the shape of papaya fruit. Moreover, surface area estimated by hand held Laser Leaf Area Meter was nearest to geometrical surface area of papaya than Surface area by leaf Image analyser.

The average surface area of papaya $\mathrm{cv}$. Red Lady and cv. Local were $574.81 \mathrm{~cm}^{2}$ and $400.12 \mathrm{~cm}^{2}$, respectively, at different stages of ripening. The geometric surface area of papaya calculated from the assumed composite geometrical shape, when compared with surface area estimated by wrapping and scanning method through leaf Image analyzer (LIASA) and hand held Laser Leaf Area Meter (LLAMSA), were accurate up to $97.47 \%\left(\mathrm{C}_{1} \mathrm{~S}_{1}\right)$ and $98.73 \%\left(\mathrm{C}_{1} \mathrm{~S}_{3}\right)$ for cv. Red Lady and $97.88 \%\left(\mathrm{C}_{2} \mathrm{~S}_{4}\right)$ and $99.52 \%\left(\mathrm{C}_{2} \mathrm{~S}_{3}\right)$ for cv. Local, respectively.

\section{References}

Anadaraj, M.; Bhagavan, S. (1983) A simple method to determine the surface area of areca fruits (Areca catechu L.) Journal of Plantation Crops, v.11, p.165-166, 1983.

Athmaselvi, K. A., Jenney P., Pavithra C. and Roy I. (2013) Physical and biochemical properties of selected tropical fruits. Int. Agrophys., 28:383-388.

Clayton, M.; Amos, N.D.; Banks, N.H.; Morton, R.H. (1995) Estimation of apple fruit surface area. New Zealand Journal of Crop and Horticultural Science, v.23, p.345-349.

Dias-Perez, J.C. (1998) Transpiration rates in eggplant fruit as affected by fruit and calyx size. Postharvest Biology and Technology, v.13, p.45-49.

Padmanaban, B.; Daniel, M.; Jose, C.T. (1997) A non-destructive method to estimate surface area of areca fruit for entomological studies. Journal of Plantation Crops, v.25, p.103-105. 
Timmer, L.W., Zitko, S.E. Albrigo, L.G. (1998) Split applications of copper fungicides improve control of melanose on grapefruit in Florida. Plant Disease, v.82, p.983-986.
Yang, Y.; Allen, J.C.; knapp, J.L.; Stansly, P.A. (1997) An age-structured population model of citrus rust mite: a fruit-mite-fungal pathogen system. Ecological Modelling, v.104, p.71-85,

\section{How to cite this article:}

Kher R. M., F. M. Sahu, S. N. Singh and Patel V. A. 2018. Estimation of Surface Area of Papaya Fruits. Int.J.Curr.Microbiol.App.Sci. 7(11): 3601-3607. doi: https://doi.org/10.20546/ijcmas.2018.711 